\title{
Evaluating serum C-reactive protein level in patients with chronic obstructive pulmonary disease and its correlation with disease severity
}

\author{
Alireza Moayyedkazemi ${ }^{1}{ }^{*}$, Mohammad Hossein Rahimirad ${ }^{2}$
}

${ }^{1}$ Department of Internal Medicine, Lorestan University of Medical Sciences, Khorramabad, Iran

${ }^{2}$ Department of Internal Medicine, Urmia University of Medical Sciences, Urmia, Iran

\section{Correspondence}

Alireza Moayyedkazemi, Department of Internal Medicine, Lorestan University of Medical Sciences, Khorramabad, Iran

Email: amr.kazemi@yahoo.com

History

- Received: 20 July 2018

- Accepted: 14 October 2018

- Published: 05 November 2018

DOI :

https://doi.org/10.15419/bmrat.v5i11.494

\section{Check for updates}

\section{Copyright}

( ) Biomedpress. This is an openaccess article distributed under the terms of the Creative Commons Attribution 4.0 International license.

\begin{abstract}
Background: It has been proven that patients with chronic obstructive pulmonary disease (COPD) are at risk for increased atherothrombotic events. Studies have demonstrated that C-reactive protein (CRP) and COPD are risk factors for heart disease. The present study aimed to evaluate the serum level of CRP in patients with COPD and compare it with those of the control group.

Method: The present case-control study was conducted on 40 patients with COPD and 51 asymptomatic individuals (control subjects). High-sensitivity C-reactive protein (hsCRP), blood gases, and spirometry were evaluated in patients with COPD and compared with those of the control group. Results: Patients with COPD had a higher hsCRP than the control group, and the difference was statistically significant $(7.6 \mathrm{mg} / \mathrm{L}$ compared to $4.2 \mathrm{mg} / \mathrm{L}, \mathrm{P}<0.001)$. A negative correlation was found between hsCRP and the predicted percentage of forced expiratory volume in one second (FEV1\%) $(P=0.03 ; r=0.32)$. There was also a positive correlation between hsCRP and the severity of COPD based on the Global Initiative for Chronic Obstructive Lung Disease (GOLD) criteria ( $P=0.04 ; r=0.3$ ). Conclusion: Serum hsCRP is higher in the COPD group than the control group matched based on age, and hsCRP is correlated with the severity of COPD. Further studies with larger sample sizes are required for evaluating this correlation in patients with COPD.
\end{abstract}

Key words: CRP, Iran, Pulmonary disease, Smoking

\section{INTRODUCTION}

Chronic obstructive pulmonary disease (COPD) is considered a common type of lung disease characterized by airflow restriction and serious long-term breathing problems ${ }^{1}$. The maintainable decrease in the expiratory pressure flow is the main feature in COPD. Studies have shown that inflammation plays a significant role in the pathogenesis of COPD. Moreover, it has been proven that in the final stages of COPD, long after the cessation of smoking, the inflammation induced by smoking in the early stages of the disease still persists ${ }^{1}$. Studies have reported that the association between decreased pulmonary function and the intensity of smoking demonstrates an increase in COPD as patient age increases, thus confirming a direct correlation between smoking and $\mathrm{COPD}^{2}$. On the other hand, indoor exposure to biomass smoke, such as wood, fertilizer, remaining products and charcoal, can result in acute respiratory problems in children as well as in COPD and lung cancer in women, such that it causes nearly $2.7 \%$ of the disability-adjusted life years (DALYS) worldwide ${ }^{3}$. Approximately, more than $50 \%$ of the world's population uses biomass for cooking, heating or baking bread, whereas previous studies have shown the direct correlation between biomass smoke, chronic bronchitis and $\mathrm{COPD}^{3}$. Based on the World Health Organization (WHO) reports, COPD is a common disease that will be recognized as the $5^{\text {th }}$ most common disease and the 3rd leading cause of death globally by 2020. This may be a result of the reduced mortality rate caused by cardiovascular diseases in developed countries as well as decreased infectious causes in developing countries, in addition to a considerable growth in smoking and environmental pollution ${ }^{1}$.

C-reactive protein (CRP) is an acute-phase protein mainly produced in the liver in response to tissue damage and inflammation. CRP reflects the overall burden of inflammation in the body of patients with COPD in exacerbation and stable conditions. CRP is also a predictor for hospitalization and mortality in chronic respiratory failure ${ }^{4,5}$. Most studies on the risk factors and causes of COPD, such as CRP, were conducted in developed countries. No study has been conducted in Iran given its different lifestyle and dietary habits, such as the use of vitamins and antioxidants $^{6-8}$. It is assumed that high-sensitivity $\mathrm{C}$-reactive protein (hsCRP) is increased in patients 
with COPD, and that there is a relationship between plasma CRP level (on the one hand), and the severity of COPD and quality of life (on the other hand) in these patients. The aim of the present study was to evaluate the serum level of hsCRP and assess its correlation with lung function parameters in patients with COPD.

\section{METHODS}

\section{Patients}

In this study, the target population was considered as all patients with COPD who were diagnosed by diagnostic tests (spirometry). The prospective data were collected from 40 COPD patients who were admitted to the Pulmonary Ward, Imam Khomeini Hospital, Urmia, in 2013. Additionally. 51 asymptomatic individuals were selected as the control group. COPD patients underwent spirometry tests and the severity of disease was determined by the Global Initiative for Chronic Obstructive Lung Disease (GOLD) criteria.

\section{Ethics}

This study was approved by the Ethics Committee of Urmia University of Medical Sciences, Urmia, Iran. An informed consent was taken by all participants.

\section{Study design}

The main inclusion criteria for COPD patients were having symptoms or history of COPD with FEV1/FVC below 70\% after using a bronchodilator. Diseases such as hemoptysis, pneumothorax, acute coronary disease, recent MI, pulmonary embolism, vascular aneurysm, recent surgery, acute infection, history of malignancy, or any inflammatory process other than COPD, were the exclusion criteria for COPD patients. The inclusion criteria for the control group were those of age 55 years old or older, with no signs of the exclusion criteria of the COPD group, and no history of COPD, shortness of breath, or coughing.

\section{Procedure}

In this study, all individuals in the control and COPD groups were visited, all individuals were examined, and their history taken. The information was entered into a special form. For all subjects, information such as age, sex, history of smoking, baking, medical history of the patient, as well as the vital signs, were recorded. In the COPD group, the patient's tests (including $\mathrm{CBC}$ and biochemistry) were examined, and if patients had any of the exclusion criteria, they were excluded. In the control group, patients were selected based on examination and history, and in case of a history of earlier diseases, they were excluded based on the exclusion criteria. In both groups, the individuals underwent blood sampling, and the serum sample of the patients was centrifuged. For each individual, 3 samples were separated to measure hsCRP, and one sample was separated as a backup. The samples were stored at $-20^{\circ} \mathrm{C}$ until further use.

\section{hsCRP assessment}

HsCRP was measured in 40 COPD patients and 48 control patients. Due to the sensitivity of the hsCRP measurement, the hsCRP was measured three times for each sample, and the mean was considered as the averaged results of hsCRP. Serum hs-CRP was measured by immunoturbidometry assay (Roche Diagnostics, Mannheim, Germany) and an auto analyzer (Lysis, Milan, Italy), with a normal value defined as < $5000 \mathrm{ng} / \mathrm{L}$.

In this study, there was no specific ethical considerations. The information about each person was entered in a special form, and finally, the collected information of both groups were compared based on t-test. Moreover, the Pearson correlation coefficient was used to examine the correlation between variables.

\section{Statistical analysis}

Statistical analysis was carried out using SPSS 17.0 software (SPSS Inc., Chicago, IL, USA). Descriptive statistics were indicated as percent (for categorical) and mean (SD) (for continuous) variables. We used $t$-test to compare the values between groups; with $P<0.05$ set as the level of statistical significance.

\section{RESULTS}

In this study, 91 subjects were investigated (40 patients with COPD and 51 individuals as controls). The COPD group consisted of 22 men (55\%) and 18 women $(45 \%)$, whereas the control group was comprised of 29 men (56\%) and 22 women (43\%). Thus, the COPD and control groups were matched in terms of sex. There was no significant difference between these two groups. The mean age was $66.98 \pm 10.3$ years in the COPD group and $66.02 \pm 8.7$ years in the control group. Therefore, the COPD and control groups were matched in terms of age.

In the COPD group, 23 subjects (57.5\%) noted cigarette smoking during the study, 7 subjects (17.5\%) reported cigarette smoking in the past, and 14 subjects (35\%) mentioned a history of baking. In the control group, 8 subjects (15.7\%) noted cigarette smoking during the study; 4 subjects $(7.8 \%)$ mentioned 
cigarette smoking in the past, and five subjects (9.8\%) reported a history of baking. In the control group, 34 patients $(66.6 \%)$ had no history of smoking or baking. In this study, hsCRP was measured in 40 patients with COPD and 48 control subjects. The mean hsCRP was $7619 \pm 407 \mathrm{ng} / \mathrm{mL}$ in the COPD group and $2774 \pm 383$ $\mathrm{ng} / \mathrm{mL}$ in the control group. In the comparative study of the two groups using t-test, a significant difference was observed $(\mathrm{p}<0.001)$.

The COPD group underwent spirometry and blood gas measurements, and then FEV1, FEV1\%, FVC, and FEV1/FVC parameters were measured. The severity of the disease was determined by the GOLD criteria, where 12 subjects (30\%) were GOLD II, 19 subjects (47.5\%) were GOLD III, and nine subjects $(22.5 \%)$ were GOLD IV. There was no case of GOLD I found among the subjects because patients were hospitalized. Mean FEV1 was $1.5 \mathrm{~L} / \mathrm{s}$, mean FVC was 2.026 l, and mean FEV1/FVC was $57.3 \%$.

The correlation between serum hsCRP and age, FEV1, $\mathrm{PaO}_{2}$, and FEV1/FVC was studied in patients with COPD, where the Pearson correlation coefficients between hsCRP and the above-mentioned variables equaled $0.171,0.093,-0.329$, and -0.061 , respectively $(\mathrm{P}<0.05$ in the correlation between hsCRP and FEV1, and $\mathrm{P}>0.2$ in other cases).

Regarding smoking and its relationship with the serity of COPD, 23 patients reported as current smokers, where nine subjects had moderate COPD, 12 subjects had severe COPD, and two subjects had very severe COPD. In this category, there was a significant relationship between the severity of COPD and current smoking $(\mathrm{P}=0.042)$. Furthermore, 7 subjects reported as past smokers. In this group, there was a significant correlation between the severity of COPD and a history of smoking $(\mathrm{P}<0.001)$. Moreover, from among patients with COPD, 14 patients noted a history of baking. In this group, there was no significant correlation between the severity of COPD and a history of baking $(\mathrm{P}=0.243)$. The correlation between hsCRP in patients with COPD was $r=0.035$, and the correlation between hsCRP in the control group was $r=0.001$.

\section{Evaluating the correlation between hsCRP and the severity of COPD}

The correlation between the severity of COPD and hsCRP equaled $\mathrm{r}=0.315(\mathrm{P}=0.048)$. Therefore, there is a significant correlation between the severity of COPD and hsCRP. There is also a significant correlation between hsCRP and the severity of COPD.

\section{DISCUSSION}

In this study, serum hsCRP level was measured in COPD patients and control subjects, and the correlation between partial pressure of oxygen $\left(\mathrm{PaO}_{2}\right)$, FEV1, and age was examined with the abovementioned blood factor. Serum CRP (SCRP) is a risk factor for cardiovascular and thromboembolic diseases ${ }^{9}$, and in patients with COPD, the pulmonary inflammation apparently leads to systemic inflammation because the use of inhaled corticosteroids in these patients has been associated with a decrease in SCRP and other markers of systemic inflammation ${ }^{10}$. It is observed that in these patients, SCRP $>3 \mathrm{mg} / \mathrm{L}$ is associated with a ten-year increase in mortality ${ }^{11}$.

In this study, the hsCRP level was measured for the control and COPD groups. CRP increases the risk of thrombotic events and cardiovascular mortality. In the lungs, CRP has a protective function against bacteria and apoptotic cells in the form of an intrinsic immune system. At first, CRP is produced by hepatocytes in the liver in response to IL-6, and then enters the lungs through the plasma. The inflammation in COPD activates epithelial cells and increases alveolar macrophages and other inflammatory cells which are responsible for the release of IL-6. This in turn leads to an acute phase response and an increase in plasma CRP. Moreover, IL-6 regulates two other acute phase reactors, namely fibrinogen and al-anti trypsin, both of which affect the pathogenesis of COPD ${ }^{11}$. In further support of IL-6 in the development of COPD, studies have revealed that IL- 6 increases the number of CD8 and CD4 cells, macrophages, B cells, and pulmonary neutrophils, which are matched with changes seen in the pathology of COPD. On the other hand, an increase in IL-6 leads to airspace enlargement in emphysema, peribronchial accumulations, monocellular cells, increased wall thickness of airways, subepithelial fibrosis, and increased airway response. In animals, a contact with ozone decreases IL- 6 and, consequently, reduces pulmonary injury. Therefore, plasma CRP is associated with IL-6-dependent processes in airways, leading to the progress of COPD and severe clinical problems ${ }^{11,12}$.

In this study, to eliminate the role of infection in increasing CRP, all patients with abnormal CXR (indicating pneumonia) who were febrile or had leukocytosis were excluded. In this study, consistent with the study by Tores et al. (2006), in Spain, and Seemungal et al. (2007), the mean hsCRP level between control group and COPD group was different by greater than $3.3 \mathrm{mg} / \mathrm{L}$, which was significant $(\mathrm{P}<0.001)^{13,14}$. A significant negative correlation between hsCRP and 
Table 1: Demographic characteristics and studied variables among COPD patients and asymptomatic individuals (control group)

\begin{tabular}{lccc}
\hline \multicolumn{1}{c}{ Variables } & Control & COPD & P-value \\
Age & $66.02 \pm 8.7$ & $66.98 \pm 3.10$ & 0.63 \\
Gender & & & \\
Male & $29(56.9 \%)$ & & \\
Female & $22(43.1 \%)$ & $18(45 \%)$ \\
Smoking & & \\
Now smoking & $8(15.7 \%)$ & $23(57.5 \%)$ \\
Past smoking & $4(7.8 \%)$ & $7(17.5 \%)$ & \\
Baking & $5(9.8 \%)$ & $14(35 \%)$ \\
Lung Function & & \\
FEV1/L & - & 1.15 & \\
FVC/L & - & $57.3 \%$ & \\
FEV1/FVC & $4277 \pm 383$ & $7619 \pm 407$ & \\
hcCRP $(\mathbf{m m o l} / \mathrm{L})$ & & & \\
\hline
\end{tabular}

${ }^{*} \mathrm{P}<0.05$; statistically significant

Table 2: Smoking and its relationship with severity of COPD

\begin{tabular}{lccccc}
\hline & & COPD severity & & \\
& $\begin{array}{c}\text { Moderate } \\
\text { No. (\%) }\end{array}$ & $\begin{array}{c}\text { Severe } \\
\text { No. (\%) }\end{array}$ & Very severe \\
& $9(39.1)$ & $12(52.2)$ & No. (\%) & Total & P-value \\
Now smoking & - & $1(14.3)$ & $2(8.7)$ & 23 & 0.042 \\
Past smoking & $5(35.7)$ & $8(57.2)$ & $6(85.7)$ & 7 & $<0.001^{*}$ \\
Baking & & $1(7.1)$ & 14 & 0.243 \\
\hline${ }^{*} \mathrm{P}<0.05$; statistically significant & & & &
\end{tabular}

FEV1\% was found in this research study $(\mathrm{r}=0.32$, $\mathrm{P}=0.3)$. A similar correlation was also reported between FEV1\% and hsCRP by Fimognari et al. (2007) $(\mathrm{r}=0.39, \mathrm{P}=0.01)$, which is also consistent with the results from a study by Seemungal et al. (2009) ${ }^{13,15}$.

\section{CONCLUSION}

The findings of the present study demonstrated that plasma CRP is not only effective in the evaluation of inflammation in COPD, but also useful as a marker in monitoring inflammation during COPD treatment. CRP is decreased during treatment by inhaled corticosteroids. Moreover, the evaluation of the possible deficiency of vitamin B12 and folic acid is recommended in patients with COPD, in addition to the evaluation of the serum level of IL-6 in patients with COPD exacerbation. Furthermore, evaluating nutritional status, BMI, and serum albumin and their correlation with the outcome of the disease is required in patients with COPD.

\section{COMPETING INTERESTS}

The authors declare no conflict of interest in this study.

\section{AUTHORS' CONTRIBUTIONS}

AM: Study design, data collection, data analysis, writing

MHR: data analysis; writing

\section{ACKNOWLEDGMENTS}

We would like to thank from the staff of Imam Khomeini Hospital (Urmia, Iran) to help us in data collection.

\section{LIST OF ABBREVIATIONS}

CBC: Complete blood count COPD: Chronic obstructive pulmonary disease CRP: C-reactive protein 
FEV1: Forced expiratory volume

FVC: Forced vital capacity

GOLD: Global Initiative for Chronic Obstructive Lung Disease

\section{REFERENCES}

1. Decramer M, Janssens W, Miravitlles M. Chronic obstructive pulmonary disease. Lancet. 2012;379:1341-51. null. Available from: Doi:10.1016/s0140-6736(11)60968-9.

2. Rabe KF, Hurd S, Anzueto A, Barnes PJ, Buist SA, Calverley P, et al. Global strategy for the diagnosis, management, and prevention of chronic obstructive pulmonary disease: GOLD executive summary. American Journal of Respiratory and Critical Care Medicine. 2007;176:532-55. null. Available from: DOI:10.1164/rccm.200703-456SO.

3. Barnes PJ. Chronic obstructive pulmonary disease. The New England Journal of Medicine. 2000;343:269-80. null. Available from: Doi:10.1056/nejm200007273430407.

4. Joppa P, Petrasova D, Stancak B, Tkacova R. Systemic inflammation in patients with COPD and pulmonary hypertension. Chest. 2006;130:326-33. null. Available from: DOI:10.1378/ chest.130.2.326.

5. Chaouat A, Savale L, Chouaid C, Tu L, Sztrymf B, Canuet M. Role for interleukin- 6 in COPD-related pulmonary hypertension. Chest. 2009;136:678-87. null. Available from: DOI: 10.1378/chest.08-2420.

6. Ballou SP, Lozanski G. Induction of inflammatory cytokine release from cultured human monocytes by C-reactive protein. Cytokine. 1992;4:361-8. null. Available from: Doi: 10.1016/1043-4666(92)90079-7.

7. Cermak J, Key NS, Bach RR, Balla J, Jacob HS, Vercellotti GM. C reactive protein induces human peripheral blood monocytes to synthesize tissue factor. Blood. 1993;82:513-20. null.

8. Schnyder G, Roffi M, Flammer Y, Pin R, Hess OM. Effect of homocysteine-lowering therapy with folic acid, vitamin B12, and vitamin B6 on clinical outcome after percutaneous coro- nary intervention: the Swiss Heart study: a randomized controlled trial. Journal of the American Medical Association. 2002;288:973-9. null. Available from: DOI:10.1001/jama.288 8.973.

9. Zakai NA, Katz R, Jenny NS, Psaty BM, Reiner AP, SM S, et al. Inflammation and hemostasis biomarkers and cardiovascular risk in the elderly: the Cardiovascular Health Study. Journal of thrombosis and haemostasis. 2007;5:1128-1135.

10. Sin DD, Lacy P, York E, Man SF. Effects of fluticasone on systemic markers of inflammation in chronic obstructive pulmonary disease. American Journal of Respiratory and Critical Care Medicine. 2004;170:760-5. null. Available from: DOI:10.1164/rccm.200404-543OC.

11. Dahl M, rgen Vestbo J, Lange $P$, Bojesen SE, Tybjærg-Hansen $A$, rge $G$ Nordestgaard B. C-reactive protein as a predictor of prognosis in chronic obstructive pulmonary disease. American Journal of Respiratory and Critical Care Medicine. 2007:175:250-255.

12. Stolz D, Christ-Crain M, Morgenthaler NG, Leuppi J, Miedinge D, Bingisser R. Copeptin, C-reactive protein, and procalcitonin as prognostic biomarkers in acute exacerbation of COPD. Chest. 2007;131:1058-67. null. Available from: DOI: 10.1378/chest.06-2336.

13. Seemungal TA, Lun JC, Davis G, Neblett C, Chinyepi N Dookhan C. Plasma homocysteine is elevated in COPD patients and is related to COPD severity. International Journal of Chronic Obstructive Pulmonary Disease. 2007;2:313-21. null. Available from: Doi:10.2147/copd.s2147.

14. de Torres JP, Cordoba-Lanus E, López-Aguilar C, de Fuentes MM, de Garcini AM, Aguirre-Jaime A. C-reactive protein levels and clinically important predictive outcomes in stable COPD patients. The European Respiratory Journal. 2006;27:902-7. null. Available from: Doi:10.1183/09031936.06.00109605.

15. Fimognari FL, Loffredo L, Simone SD, Sampietro F, Pastorelli $R$ Monaldo $\mathrm{M}$, et al. Hyperhomocysteinaemia and poor vitamin B status in chronic obstructive pulmonary disease. Nutrition, Metabolism and Cardiovascular Diseases. 2009;19:654-659. 